\title{
A dissecação como ferramenta pedagógica no ensino da Anatomia em Portugal
}

Over the course of history, there has not been any consensus regarding the importance of using human cadavers for educational and research purposes. In the past, to obtain the cadavers essential for teaching, it was necessary not only to use cadavers of the condemned and those not claimed by their families, but also to steal and/or purchase corpses. These solutions, besides being ethically and legally inadmissible, always proved to be insufficient for the needs of medical schools. Over the last few decades, global awareness of the legitimacy of cadaver donation has gradually increased, and this is considered today to be the dignified way to fill this need. This article presents a historical, legal and pedagogical review of the literature on the importance of using of human cadavers in the teaching of human anatomy in medical schools, including in Portugal, especially the role of cadaveric dissection complementarily with other teaching tools.

Keywords: Anatomy. Cadaver. Dissection. Donation. Medical education.
Ao longo da História, a importância da utilização de cadáveres humanos para o ensino e investigação não tem sido consensual. No passado, a obtenção dos cadáveres indispensáveis ao ensino passou pelo recurso a cadáveres de reclusos, de não reclamados e ao roubo e/ou compra. Para além da inadmissibilidade ética e jurídica destas soluções, estas revelaram-se insuficientes para as necessidades das escolas médicas. Nas últimas décadas, a consciência global da legitimidade da doação de cadáveres foi-se intensificando, considerando-se, hoje, a forma digna de colmatar essa falta. Neste artigo realizou-se uma revisão da literatura com o objetivo de se fazer uma resenha histórica, jurídica e pedagógica sobre a importância da utilização de cadáveres humanos no ensino da Anatomia Humana nos cursos de Medicina, incluindo em Portugal, nomeadamente pelo recurso à dissecação cadavérica em complementaridade com outras ferramentas pedagógicas.

Palavras-chave: Anatomia. Cadáver. Dissecação. Doação. Educação médica.

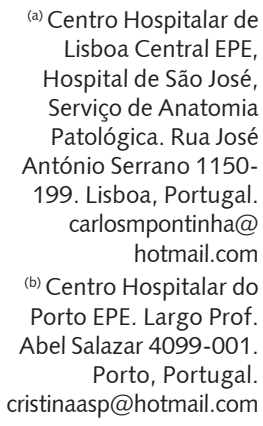
hotmail.com (b) Centro Hospitalar do Porto EPE. Largo Prof. Abel Salazar 4099-001. Porto, Portugal. cristinaasp@hotmail.com 


\section{Introdução}

A utilização de cadáveres humanos para fins de ensino médico é uma prática comum em todo o mundo e ao longo da História. Esta utilização não é, contudo, desprovida de dilemas éticos e sociais. A este propósito afirma Gouveia que "o corpo humano morto permanece numa zona de penumbra onde imperam as emoções" e que, apesar da pessoa falecida não ter personalidade jurídica, "O cadáver é um ser com direitos e deveres, tendo a relevância dos mesmos oscilado no tempo entre o plano social, o religioso, o jurídico e o científico" 1 .

\section{Objetivos}

Com este trabalho pretendemos criar um documento, em língua portuguesa, que sensibilize para a relevância da dissecação de cadáveres no ensino da Anatomia Humana. Para tal, fazemos uma breve revisão histórica sobre a utilização deste método de ensino, nomeadamente, nas faculdades de Medicina portuguesas; bem como sobre a legislação que a regulamenta em Portugal, e procuramos, ainda, refletir sobre as suas potencialidades e limitações. Este documento poderá servir de incentivo para outros médicos e académicos, naturais de países lusófonos, utilizarem e promoverem a dissecação na formação pré e pós-graduada nos seus países.

\section{Metodologia}

Foi efetuada uma pesquisa da literatura científica publicada, nas línguas portuguesa e inglesa, até março de 2013, através de bases de dados médicas, nomeadamente, Medline ${ }^{\circledR}$ e SciELO ${ }^{\circledR}$. Utilizaram-se como palavras-chave: anatomy ou medical education ou dissection. Foi também consultada uma dissertação académica defendida e aprovada numa Universidade portuguesa e a legislação relacionada com o tema. A seleção das referências bibliográficas foi feita de acordo com a sua adequação aos objetivos.

\section{Resultados}

\section{O percurso histórico da dissecação de cadáveres}

Etimologicamente, dissecar significa cortar. As primeiras dissecações de cadáveres humanos para fins científicos foram realizadas por Herófilo (Calcedónia, 335 a.C.-280 a.C.) ${ }^{2}$. No Antigo Egito (3000 a.C.30 a.C.), o desenvolvimento das práticas de embalsamamento obrigou, e motivou, o estudo da Anatomia Humana ${ }^{2}$. Aí o interesse pela Medicina era tal que a dissecação de cadáveres de animais e de humanos estava autorizada a médicos ilustres como Erasístrato (310 a.C.-250 a.C.) ${ }^{2}$. Para os hebreus, no século I a.C., o cadáver era considerado impuro e, por isso, devia ser tocado o menos possível; porém, a maioria dos conhecimentos anatómicos do Talmud provém do estudo de autópsias realizadas em criminosos e prostitutas ${ }^{1}$. Com o advir do Cristianismo, o progresso científico passou a estar sob o controlo da Igreja Católica². O Papa Bonifácio VIII (ca. 1235-1303) mandou publicar, em 1 de Março de 1300, a bula De Sepulturis, onde afirmava excomungar todos aqueles que ousassem "desmembrar um cadáver ou tirar-Ihe pela cocção a ossada" 2,3. A bula papal proibia o costume, da época, de descarnar as ossadas dos nobres que iam para a Itália com os exércitos alemães e que aí morriam, para, posteriormente, transladarem os seus restos mortais para os seus países de origem ${ }^{3}$. 
(c) Rude e agressivo pontífice.

Porém, segundo a interpretação de Letti, a bula papal não proibia a dissecação anatomica, contrariamente ao que afirmou Haller, que apelidou Bonifácio VIII de imperitus et ferox pontifex ${ }^{(\mathrm{c}) 3}$. Letti considera, aliás, que a dissecação científica de cadáveres humanos foi sempre incentivada pela Igreja, referindo, a título de exemplo, o caso de Realdo Colombo (ca. 1516-159) que estudou anatomia dissecando os cadáveres de cardeais e bispos ${ }^{3}$.

Na Europa medieval, a primeira dissecação para fins de ensino universitário é atribuída a Mondino dei Luizzi (ca. 1270-1326) no ano de 1315, na Universidade de Bolonha². Andreas Vesalius (1514-1564) utilizou corpos de condenados para efetuar as investigações que Ihe permitiram publicar, em 1543, o tratado De humanis corporis fabrica ${ }^{4}$. Segundo Gouveia, nos séculos XVI e XVII

os vivos, apesar das exceções, foram assegurando os direitos dos cadáveres quanto à proteção e respeito merecidos à inumação, à não comercialização do todo ou de partes, às exéquias fúnebres e à atenção real e espiritual prestada postumamente ${ }^{1}$.

A partir dos finais do século XVII, a dissecação cadavérica volta a assumir um lugar de destaque na progressão do conhecimento científico, devido, em grande parte, à prática da autópsia clínica tal como testemunham as obras De sedibus et causis morborum per Anatomen Indagatis (1761) de Giovanni Morgagni (16821771) e Sepulchretum sive Anatomica Pratica (1769) de Theophile Bonet (1620$1689)^{1,2}$. A grande redescoberta do valor do estudo do cadáver no século XVIII é fruto dos ideais iluministas. Este movimento cultural desenvolveu-se na Europa e assentava-se numa crença absoluta nas capacidades do Homem, iluminado pelas luzes da razão, do saber e da cultura. A luz da razão iluminaria o Homem e libertá-lo-ia do obscurantismo em que vivia mergulhado. Acreditamos que a forma como, atualmente, encaramos a dissecação para fins de ensino e investigação científica se deve à herança que este movimento nos deixou.

De acordo com Esperança Pina, a primeira referência, em Portugal, ao ensino da Medicina remonta à Idade Média, no Mosteiro de Santa Cruz, em Coimbra ${ }^{5}$. A primeira Universidade portuguesa foi criada em 1290, em Lisboa, sob a designação de Estudo Geral ${ }^{5}$. Após a transferência da instituição para Coimbra e a sua reinstalação em Lisboa, a Universidade instalou-se definitivamente em Coimbra, a partir de $1537^{5}$. Simultaneamente, no Hospital Real de Todos os Santos, que fora fundado em 1492 na cidade Lisboa, surgiu um outro foco de ensino médico através de uma "Aula de Anatomia" 5 . Em 1546, o rei D. João III (reinado, 15211557) autorizou o corregedor da Comarca de Coimbra a ceder cadáveres a D. Rodrigo de Reinosa, Lente de Prima da Universidade, para realizar estudos anatómicos ${ }^{1,2}$. Os Estatutos Pombalinos da Universidade de Coimbra (1563) dispunham que, para uso da Anatomia, "servirão os cadáveres dos que morressem nos Hospitais e dos condenados e, na falta de ambos, servirão os cadáveres de quaisquer pessoas que falecessem na cidade de Coimbra" 2 . O Marquês de Pombal, Sebastião José de Carvalho e Melo (1699-1782), Secretário de Estado do rei D. José (reinado, 1750-1777), reconheceu o atraso intelectual da sociedade portuguesa e quis modernizá-la segundo os princípios do lluminismo,

promovendo, para isso, importantes reformas no ensino, em particular da Ciência, rompendo com a tradição escolástica medieval ${ }^{2}$. A ligação histórica entre Portugal e o Brasil atribui, ao primeiro país, responsabilidades na introdução da dissecação no ensino médico brasileiro. De acordo com as políticas da época, criar uma escola de Medicina nas colónias portuguesas poderia promover sentimentos de independência ${ }^{6}$. Por isso, o Reino optou por ensinar apenas os princípios teóricos 
fundamentais, sendo o ensino essencialmente prático. Os estudantes que tivessem condições económicas poderiam, posteriormente, acabar os seus estudos na metrópole e, assim, obter o título de médicos. Em 1768, foi feita a primeira tentativa de criar um curso de Anatomia na vila brasileira de Sabará, porém o rei D. José não o autorizou. Em 1808, foi autorizada a "Aula de Anatomia e Cirurgia de Vila Bela", cujo programa curricular incluía a dissecação de cadáveres durante os dois anos inteiramente dedicados à Anatomia ${ }^{6}$.

Já no século XX, em Portugal, Henrique de Vilhena (1879-1958), fundador e primeiro diretor do Instituto de Anatomia da Faculdade de Medicina da Universidade de Lisboa, que fora criado em 1911, defendeu a "dissecação cadavérica como método de ensino e investigação" 7 . O desenvolvimento das técnicas operatórias levou, naquela altura, à divisão do ensino da Anatomia em Anatomia Descritiva e Anatomia Topográfica ${ }^{7}$. Recentemente, o número de cursos de pós-graduação na área da Medicina aumentou em Portugal ${ }^{8}$. Em 2012, em vários destes cursos utilizou-se material cadavérico. Algumas das faculdades que mais recorrem a esta ferramenta de ensino são a Faculdade de Ciências Médicas da Universidade Nova de Lisboa, a Faculdade de Medicina da Universidade de Coimbra e a Faculdade de Medicina da Universidade do Porto ${ }^{8}$.

\section{A legislação portuguesa: da Portaria no 40 de 1913 ao Decreto-Lei n 274/99}

Em Portugal, em 1913, os legisladores já reconheciam as "dificuldades que sofria o ensino pelo pequeno número de cadáveres deixados pelos serviços hospitalares" à disposição das universidades ${ }^{9}$. Tal reconhecimento justificou a Portaria $n^{\circ} 40$ desse mesmo ano, que determinava ficarem "à disposição das escolas médicas os cadáveres dos falecidos nos hospitais, asilos e casas de assistência pública, que, no prazo de 24 horas após o falecimento, não tivessem sido reclamados pelas famílias para procederem à sua inumação" 9 . No final da década de 1980, eram já poucos os cadáveres que davam entrada nas escolas médicas portuguesas².

Apesar dos percalços, a atual legislação é muito generosa, pois prevê, nos artigos $3^{\circ}$ (Atos permitidos), $4^{\circ}$ (Legitimidade) e $5^{\circ}$ (Manifestação de disposição) do Decreto-Lei n. ${ }^{\circ}$ 274/99 de 22 de julho de 1999, que, e citando as palavras de Gouveia, “o próprio, em vida, doe o seu cadáver ao ensino e à Ciência, negue a sua utilização (através do RENNDA - Registo Nacional de não Dadores) ou que nada diga"1,10. Prevê também, nesta última situação, que a família ou quem de direito seja soberano, disponha do corpo do ente falecido nas primeiras 24 horas após a tomada de conhecimento do óbito. Este Decreto-Lei abriu o leque de possibilidades, mas os resultados não foram imediatos. Desde que o mesmo entrou em vigor, o número de doações tem aumentado consideravelmente ${ }^{8}$. Contudo, por vezes, os familiares não cumprem a vontade expressa pelos doadores, o que explica, em parte, a disparidade existente entre o número de doações e o número de corpos efetivamente entregues às universidades ${ }^{8}$. Isto porque, apesar de o $\mathrm{n}^{\circ} 2$ do artigo $4^{\circ}$ (Legitimidade) afirmar que "a reclamação só é atendida após a eventual utilização do cadáver para fins de ensino", permitindo respeitar a vontade do falecido e, consequentemente, melhorar as condições no ensino prático da anatomia humana, logo acresce o $\mathrm{n}^{\circ} 3$ que "o cadáver não pode ficar retido mais de 15 dias", intervalo de tempo claramente insuficiente para o fim a que se destina o mesmo ${ }^{9}$. É de referir que a utilização de cadáveres para fins de ensino e investigação científica em nada prejudica as cerimónias fúnebres que antecedem o ato de doação. Para além disso, a entidade cientificamente beneficiada fica responsável pela cremação ou inumação dos restos mortais, tal como é preconizado nos artigos $16^{\circ}$ (Transporte) e $18^{\circ}$ (Destino dos despojos) do atual Decreto-Lei ${ }^{9}$. É importante mencionar que a experiência dos últimos 13 anos demonstrou que a atual legislação possui algumas insuficiências/deficiências que deveriam, na medida do possível, ser corrigidas/eliminadas numa futura, e já prevista, revisão da mesma.

\section{O "valor" pedagógico da dissecação cadavérica}

Nas últimas três décadas, em face do grande desenvolvimento da Biologia Celular, da Bioquímica e da Genética, algumas escolas médicas têm optado por condensar os curricula das ciências morfológicas (Anatomia, Histologia e Embriologia), outras recorreram a novas metodologias, como o ensino baseado 
em problemas, e outras ainda agruparam os conteúdos programáticos das diferentes ciências básicas em unidades curriculares organizadas por sistemas orgânicos ${ }^{10-13}$. Tais opções poderão conduzir ao abandono da dissecação, pois esta exige tempo e investimento económico ${ }^{13,14}$. O ensino da Anatomia Humana pode estar hoje, em algumas faculdades, abaixo daquilo que se considera seguro e adequado para futuros médicos ${ }^{12,13}$. Turney refere que apesar de a maioria dos cirurgiões não necessitar de dissecar um cadáver para conseguir operar um doente, tal experiência aumentará o seu conhecimento sobre o que está a fazer e porque o está a fazer, o que beneficiará quer o médico quer o doente ${ }^{13}$. A dissecação permite não só aprender o detalhe anatómico como também familiariza o aluno com a variação morfológica ${ }^{13}$. A variação em Anatomia deve ser entendida como a anatomia normal, pois nenhum indivíduo é exatamente igual a outro. Por isso, a Escola Médica de Hannover colocou, nas paredes do seu laboratório de dissecação, imagens de variantes do sistema vascular arterial ${ }^{15}$. Deste modo, os docentes incentivam os alunos a compararem, enquanto dissecam, os seus achados com aquelas variações ${ }^{15}$.

Os métodos e materiais de ensino têm evoluído ao longo dos tempos ${ }^{13,16}$. A Anatomia Humana pode ser ensinada, hoje, recorrendo a ilustrações em papel, fotografias e/ou a sistemas de imagem digital ${ }^{13,16}$. Os computadores permitiram tornar as imagens estáticas a 2D numa exploração dinâmica a $3 \mathrm{D}^{16}$. De referir, que qualquer método de ensino utilizado em Medicina deve promover quer o desenvolvimento científico quer o humano do aluno ${ }^{14}$. É, por isso, importante avaliar a dissecação de modo holístico. Com base neste pressuposto, Martyn et al. tentaram perceber o impacto emocional da dissecação em 16 estudantes universitários após estes terem dissecado, pela primeira vez, corações e encéfalos humanos ${ }^{17}$. Alguns estudantes referiram terem-se sentido emocionados quando removeram o coração do mediastino pois associam este órgão às emoções, enquanto seis estudantes afirmaram ser "estranho" dissecar o encéfalo visto ser o órgão responsável "pelas pessoas serem quem são" 17. Os investigadores concluíram que a dissecação contribui para o desenvolvimento pessoal dos alunos e que existem algumas regiões do corpo humano que lhes são mais difíceis dissecar pois albergam órgãos cultural e simbolicamente significativos ${ }^{17}$. Arraéz-Aybar et al. estudaram, na Universidade Complutense de Madrid, os níveis de ansiedade dos estudantes durante as aulas de dissecação ${ }^{18}$. Os investigadores concluíram que, na primeira aula, todos os estudantes apresentaram um aumento dos seus níveis de ansiedade, que, com a sucessão das aulas, foi diminuindo. Enquanto o estado ansioso associado à primeira aula depende, em grande parte, das condições em que esta é feita, bem como com a informação prévia que foi transmitida aos alunos, já os níveis de ansiedade nas aulas posteriores dependem, sobretudo, do perfil psicológico de cada aluno ${ }^{18}$. Os investigadores confirmaram que mostrar, aos alunos, previamente, vídeos da atividade que vão realizar diminui os níveis de ansiedade ${ }^{18}$. As aulas de dissecação devem, também, ser aproveitadas para os docentes transmitirem valores éticos e humanistas que ajudem os futuros médicos a lidar, por exemplo, com a morte 14,15,18. $^{2}$.

Mais importante do que defender a utilização da dissecação será, talvez, conciliar as diferentes metodologias com o objetivo de melhorar o processo de ensino ${ }^{13}$. A aprendizagem da Anatomia exige um equilíbrio entre a memorização, a compreensão e a visualização, sendo que as estratégias educativas que visem uma aprendizagem de profundidade correlacionam-se positivamente com melhores qualificações finais ${ }^{19}$. Fornaziero et al. defendem que sejam utilizadas as metodologias mais inovadoras em conjunto com as clássicas ${ }^{10}$. A dissecação é, segundo estes autores, um excelente método para desenvolver a capacidade de resolver problemas clínicos; por sua vez, as novas tecnologias permitem a animação de certos fenómenos biológicos que facilitam a sua compreensão ${ }^{10}$. Marker et al. desenvolveram um currículo de Anatomia Radiológica, que foi incluído na disciplina de Anatomia, onde era proposto, aos alunos, que aplicassem os seus conhecimentos na identificação das estruturas presentes em imagens de radiografia, de tomografia computorizada e de ressonância magnética ${ }^{20}$. Os alunos consideraram esta abordagem não só útil como estimulante, pois aproxima-os da sua futura atividade clínica ${ }^{20}$. Também Rizzolo et al. consideram positiva a integração da Anatomia Radiológica nos currícula de Anatomia ${ }^{21}$. Pabst sugere que sejam também fornecidas, aos alunos, imagens de endoscopia, otoscopia e ecografia ${ }^{15}$. Marker et al. aconselham, por sua vez, a criação de questionários on-line para os estudantes poderem rever, em casa, os conteúdos lecionados ${ }^{20}$.

Atualmente, a formação pós-graduada, aquela que é realizada após o curso de Medicina, é cada vez mais diversificada e visa, habitualmente, a especialização dos médicos ${ }^{11,13}$. A dissecação tem também 
um espaço neste ciclo formativo mais avançado, sobretudo nas áreas cirúrgicas ${ }^{11}$. Guvençer et al. utilizaram cabeças humanas fixadas, em detrimento de modelos animais, para praticarem procedimentos cirúrgicos utilizados no tratamento de patologias dos vasos cerebrais ${ }^{22}$. Os investigadores concluíram que este modelo é preferível, pois o padrão de vascularização é mais próximo àquele com que se irão deparar em situações reais, e que, recorrendo a bombas de perfusão que injetam agentes de contraste nos vasos sanguíneos, podem treinar as várias abordagens cirúrgicas perante perfis hemodinâmicos distintos $^{22}$. Ainda no âmbito da Neurocirurgia, Notaris et al. alertam que, apesar da dissecação virtual a 3D nunca dever substituir o treino em material cadavérico, estes métodos tecnologicamente mais avançados podem, e devem, ser utilizados em complementaridade ${ }^{23}$. Estes autores desenvolveram um modelo de treino cirúrgico para praticar abordagens endoscópicas endonasais à base do crânio baseado em três princípios: a dissecação cadavérica, um sistema virtual de simulação cirúrgica, e a análise matemática dos resultados pós-dissecação ${ }^{23}$. A dissecação tem, também, um papel importante em áreas não cirúrgicas, como a Psiquiatria, pois estes profissionais precisam de ter conhecimentos profundos em neuroanatomia ${ }^{11}$.

\section{Discussão}

A dissecação pode ser realizada num cadáver fresco, ou seja, não preservado, ou em cadáveres artificialmente conservados. Em face da escassez de material cadavérico e da necessidade de planear previamente as atividades curriculares de todo o ano letivo, a maioria das escolas médicas escolhe a segunda hipótese. Grande parte dos departamentos de Anatomia opta por embalsamar os cadáveres recorrendo a líquidos fixadores. Para tal, o sangue do cadáver é removido e substituído por um líquido fixador cuja composição varia. As soluções fixadoras contêm, habitualmente, formaldeído em concentração variável. A exposição a este químico tem sido associada ao desenvolvimento de doenças alérgicas, irritação das mucosas nasal e da orofaringe, cancro do pulmão e cancro da laringe e $^{24-26}$. Relativamente à rinite alérgica, Hisamitsu et al. concluíram, através de um estudo observacional, que apenas os estudantes com antecedentes pessoais desta patologia experimentaram alterações da função olfativa e hipersensibilidade da mucosa nasal após a dissecação ${ }^{25,26}$. Porém, estas alterações foram transitórias ${ }^{26}$. Também pode ocorrer irritação ocular e cefaleias, sobretudo quando da entrada no laboratório de dissecação $0^{25,26}$. É necessário, portanto, promover medidas preventivas que reduzam a exposição dos estudantes a esta substância. Os estudos afirmam que, em vários laboratórios de dissecação, a concentração, no ar, de formaldeído é superior aos valores máximos recomendados pela Organização Mundial de Saúde (800 ppm para locais de trabalhos em geral e 250 ppm para locais de trabalho específicos onde se manipula formaldeído) ${ }^{24}$. Para contornar este problema, a solução pode passar pela construção de laboratórios cuja arquitetura assegure uma melhor ventilação bem como a instalação, nas mesas de dissecação, de sistemas locais de ventilação e/ou de dispositivos que destruam o formaldeído ${ }^{24,25,27}$. A construção de laboratórios para este fim é um assunto que envolve, naturalmente, arquitetos, mas, também, anatomistas, dadas as suas especificidades ${ }^{27}$. Trelease sugere, por exemplo, uma configuração dos laboratórios diferente da habitual, em que as mesas de dissecação estão dispostas em " $X$ " em vez de paralelamente alinhadas, de modo a rentabilizar o espaço ${ }^{27}$. Este autor faz, ainda, uma série de considerações técnicas sobre como otimizar os sistemas de ventilação, de iluminação e como integrar equipamentos tecnológicos nas mesas de dissecação. Yamato et al. desenvolveram um sistema de ventilação para ser acoplado às mesas de dissecação convencionais e, posteriormente, ligado à ventilação geral dos laboratórios ${ }^{24}$. De modo simplista, estes investigadores conceberam uma grelha de aço com seis aberturas, através das quais são aspirados os vapores químicos $^{24}$. De seguida, estes vapores são conduzidos para uma estrutura metálica colocada debaixo da mesa de dissecação e daí reencaminhados para o circuito de ventilação geral ${ }^{24}$. Para tornar a mesa num espaço semi-fechado, colocaram, no perímetro desta, pequenas pranchas de espuma de uretano na vertical $^{24}$. Este foi o material escolhido pois é suficientemente resistente para se manter em posição e é, simultaneamente, flexível o suficiente para os estudantes poderem trabalhar com os braços sobre ele sem a amplitude dos seus gestos ficar limitada ${ }^{24}$. Assim conseguiram que, com os sistemas de ventilação 
geral e local ligados, a concentração, no ar, de formaldeído junto à mesa fosse de 405 ppm face aos 480 ppm, quando apenas o sistema geral estava a trabalhar ${ }^{24}$. Estes investigadores referem que pode não ser possível, por motivos técnicos e económicos, manter a concentração no ar de formaldeído abaixo dos $250 \mathrm{ppm}^{24}$. A tecnologia fotocatalítica tem sido estudada e desenvolvida, sobretudo com o intuito de decompor a poluição atmosférica em água e dióxido de carbono ${ }^{25}$. Omichi et al. decidiram aplicar esta tecnologia às mesas de dissecação com o objetivo de decompor os vapores de formaldeído ${ }^{25}$. Concluíram que a exposição dos estudantes ao formaldeído pode ser diminuída através deste sistema, e alertaram que este pode ser economicamente mais viável do que alterar todo um sistema de ventilação ${ }^{25}$. Outras faculdades, como a Faculdade de Ciências Médicas da Universidade Nova de Lisboa, preferem utilizar uma solução conservadora com quantidades reduzidas de formaldeído, e conservam os cadáveres em câmaras frigoríficas a temperaturas muito baixas. Esta opção permite não só diminuir a exposição dos estudantes a este agente químico, bem como manter os tecidos com um aspecto e textura mais próximos daqueles que tinham em vida, como pode assegurar o autor deste artigo que foi aluno dessa faculdade. Este método obriga, porém, a que todos os anos sejam necessários novos corpos.

Outra questão importante no âmbito da saúde ocupacional é o risco infecioso associado à manipulação de cadáveres. É dito que a maioria dos agentes infeciosos são destruídos pelos líquidos fixadores, dado o seu elevado conteúdo em formaldeído, álcool e fenol; porém, as escolas médicas devem considerar que o risco de transmissão de doenças infeciosas está sempre presente e que os cuidados preventivos nunca podem ser negligenciado ${ }^{28}$. Os principais microrganismos que podem causar doenças nestas circunstâncias são: Mycobacterium tuberculosis, vírus da hepatite B, vírus da hepatite $C$, vírus da imunodeficiência humana $(\mathrm{VIH})$ e as proteínas priónicas causadoras de encefalopatias espongiformes transmissíveis ${ }^{28}$. A dissecação só deve ser autorizada aos estudantes equipados com material de proteção individual (bata, luvas e máscara). Após o procedimento, todos os instrumentos cirúrgicos devem ser higienizados recorrendo a um sistema de autoclave ou, em alternativa, fervendo-os durante, pelo menos, três minutos numa solução de dodecil sulfato de sódio a $3 \%{ }^{28}$. Se os instrumentos forem de alumínio, não é recomendado utilizar soluções de hidróxido de sódio e, no caso de serem de aço, deve-se ter em conta que o hipoclorito de sódio é corrosivo ${ }^{28}$. As mesas de dissecação também devem ser limpas. Apesar de as soluções de hipoclorito de sódio serem muitas vezes utilizadas, deve ser privilegiado o uso de uma solução desinfetante que contenha fenol, pois o hipoclorito reage com o formaldeído formando éter de clorometilo, que é cancerígeno ${ }^{28}$.

Os estudantes podem aprender Anatomia dissecando corpos nunca antes dissecados, ou estudar modelos anatómicos que foram previamente dissecados e conservados. A esta última metodologia chama-se prosection, que tem a vantagem de permitir a reutilização dos modelos anatómicos, bem como permitir que pessoal mais diferenciado disseque estruturas anatómicas complexas que os alunos, dada a sua inexperiência, não conseguiriam isolar ${ }^{15,29}$. Existem estudos que comparam estes dois métodos, porém não chegam à conclusão se um é pedagogicamente superior ao outro29.

O reduzido número de cadáveres humanos para fins de ensino tem sido um problema constante ${ }^{30}$. A proveniência do material cadavérico tem variado fruto da reflexão ética e jurídica das diferentes sociedades ${ }^{30,31}$. Na Europa, os primeiros cadáveres utilizados foram os de criminosos ${ }^{1,2,31}$. Posteriormente, as escolas europeias optaram pelos cadáveres não reclamados, contudo esta forma de obter material cadavérico foi considerada vergonhosa para uma sociedade que se reclamava moderna e civilizada ${ }^{31}$. Atualmente, as faculdades de Medicina portuguesas valorizam, maioritariamente, a doação em vida. Para tal, algumas delas criaram gabinetes de apoio à doação ${ }^{8}$. Estas estruturas recebem os doadores e os seus familiares e explicam-Ihes todo o processo ${ }^{8}$. Desta forma, os doadores podem conversar com os docentes e alunos de Anatomia e, assim, compreender melhor a importância deste gesto de grande generosidade $^{8}$. A proveniência e a quantidade de material cadavérico disponível também variam entre países. Na Nigéria, por exemplo, Anyanwu et al. apuraram que 94,4\% de 18 Departamentos de Anatomia referem ter à sua disposição uma quantidade insuficiente de material cadavérico, sendo que $72 \%$ destas instituições universitárias afirmaram que mais de $90 \%$ deste material era proveniente de corpos de criminosos que foram judicialmente executados, e menos de $10 \%$ correspondiam a corpos não reclamados ${ }^{32}$. Fatores culturais foram apontados como responsáveis para não existirem doações em 
vida naquele país ${ }^{32}$. Os investigadores referem a necessidade de se criar, no seu país, legislação que regulamente a doação ${ }^{32}$. O processo de doação, além de implicar o respeito pela dignidade da pessoa humana, traduz: a multiplicidade de conflitos entre a exigência dessa dignidade, o valor da solidariedade inerente à utilização correta dos cadáveres, a possível instrumentalização indiscriminada destes, os desvios da finalidade essencial dessa utilização, e a previsão de comportamentos sociais não ajustados à atitude de respeito que os cadáveres merecem. A propósito do uso abusivo de cadáveres, podem-se referir as investigações anatómicas levadas a cabo pelo Terceiro Reich ${ }^{33}$. É, por isso, importante estarmos atentos a todos estes valores e conflitos. Para tal, é necessário que esta seja uma discussão multidisciplinar, isto é, que envolva médicos, académicos, estudantes, juristas e especialistas em Ética. A título de exemplo, o Departamento de Anatomia da Universidade Federal de Pernambuco organizou reuniões interdisciplinares, das quais resultaram vários diplomas legais e protocolos para melhorar o recebimento dos cadáveres doados e dos não reclamados ${ }^{30}$. Este departamento universitário conseguiu aumentar o número de doações divulgando a falta de cadáveres em rádios e jornais do seu Estado ${ }^{30}$.

Outra questão recorrente na literatura científica é qual deverá ser a carga horária dedicada à dissecação. Não encontrámos uma resposta consensual, pois dependerá sempre, em última análise, da carga horária total da disciplina. Num estudo publicado em 1992, a Sociedade Anatómica da GrãBretanha fez esta pergunta a 33 escolas médicas do seu país: dois terços das escolas responderam que os alunos deviam ter a oportunidade de dissecar todos os segmentos corporais, exceto áreas tecnicamente mais difíceis, como a face e o períneo; já o terço restante respondeu que dissecar apenas um segmento corporal era suficiente ${ }^{34}$. É importante discutirmos o valor pedagógico da dissecação cadavérica de forma objetiva. Winkelmann decidiu rever 14 estudos publicados em revistas indexadas, tendo selecionado apenas aqueles que quantificaram a vantagem da utilização deste método de ensino ${ }^{35}$. Winkelmann refere ser difícil analisar e comparar os diferentes estudos dados os múltiplos vieses possíveis ${ }^{35}$. Este autor conclui que é necessário desenhar estudos originais que se baseiem em variáveis que permitam avaliar, quer qualitativa quer quantitativamente, os diferentes métodos de ensino para que os académicos possam fundamentar as suas opções educativas ${ }^{35}$.

\section{Conclusão}

A Anatomia continua a ser uma das bases da formação médica, e por isso o corpo humano morto continua a desempenhar um papel central na aquisição de conhecimentos e no progresso científico ${ }^{2,25}$. A dissecação constitui uma metodologia de ensino com potencialidades únicas, pois ela é, como afirma Paula-Barbosa, "dotada de realismo e humanidade" 2 . Apesar de ser uma metodologia de ensino que exige tempo e grande consumidora de recursos económicos, a dissecação cadavérica permite que o aluno de Medicina desenvolva a sua capacidade de observação, de destreza manual, e confronta-o com dilemas de natureza ético-social que o obrigam a adotar uma postura responsável face ao outro. Em jeito de conclusão, recordemos as sábias palavras do médico português Sabino Coelho (1853-1938) quando afirmou que "O livro é muito, mas o cadáver é mais. Aquele encaminha, este mostra, aquele guia, este ensina".

\section{Colaboradores}

Carlos Marques Pontinha e Cristina Soeiro participaram, igualmente, de todas as etapas de elaboração do artigo. 


\section{Agradecimentos}

Os autores agradecem as sugestões e correções feitas pelos Professores Doutores Rosa Henriques de Gouveia e Duarte Nuno Vieira numa versão inicial deste artigo.

\section{Referências}

1. Gouveia RH. Um diálogo médico-jurídico sobre o cadáver [pós-graduação em Direito da Medicina]. Coimbra: Universidade de Coimbra; 2002.

2. Paula-Barbosa M. Proveniência do material cadavérico para fins de ensino pré e pós-graduado ao longo dos tempos: importância da doação do corpo. Papel Médico. 2000; $14: \mathrm{s} / \mathrm{p}$.

3. Letti N. Anatomia, sua história e seu intrumento de trabalho. Rev Bras Otorrinolaringol. 1972; 38(1):82-8.

4. Kickhöfel E. A lição de anatomia de Andreas Vesalius e a ciência moderna. Sci Stud. 2003; 1(3):389-404.

5. Esperança Pina M. As Faculdades de Medicina na I República. In: Garnel MRL, Alegre A, Queirós MI, editores. Corpo, Estado, Medicina e sociedade em tempo da I República. Lisboa: Imprensa Nacional da Casa da Moeda; 2010. p.30-7.

6. Jesus NM. Aulas de cirurgia no centro da América do Sul (1808-16). Hist Cienc Saude - Manguinhos. 2004; 11(1):93-106.

7. Furtado IA, Gonçalves-Ferreira AJ. O Instituto de Anatomia no centenário da Faculdade de Medicina da Universidade de Lisboa. Acta Med Port. 2011; 24(4):663-70.

8. Marques Pontinha C, Andrade FF, O'neill JG, Pais D. A dissecação cadavérica no ensino da Anatomia na Universidade Nova de Lisboa. In: Resumos do IX Congresso Nacional de Medicina Legal e Ciências Forenses; 2011; Braga; Portugal. Braga; 2011. s/p.

9. Decreto-Lei n 274/99, de 22 de julho de 1999. Dispõe sobre a utilização de cadáveres para fins de ensino e investigação científica. Brasília; 1999.

10. Fornaziero C, Gordan P, Carvaho M, Araujo J, Aquino J. O ensino da anatomia: integração do corpo humano e meio ambiente. Rev Bras Educ Med. 2010; 34(2):290-7.

11. Crisp $\mathrm{AH}$. The relevance of anatomy and morbid anatomy for medical practice and hence for postgraduate and continuing medical education of doctors. Postgrad Med J. 1989; 65(762):221-3.

12. Mckeown PP, Heylings DJA, Stevenson M, Mckelvey KJ, Nixon JR, Mcclusskey DR. The impact of curricular change on medical students' knowledge of anatomy. Med Educ. 2003; 37(11):954-61.

13. Turney BW. Anatomy in a modern medical curriculum. Ann R Coll Surg Engl. 2007; 89(2):104-7.

14. Rizzolo LJ. Human dissection: an approach to interweaving the traditional and humanistic goals of medical education. Anat Rec. 2002; 269(6):242-8.

15. Pabst R. Modern macroscopic anatomy - more than just cadaver dissection. Anat Rec. 2002; 269(5):209.

16. Trelease R. Anatomical informatics: millennial perspectives on a newer frontier. Anat Rec. 2002; 269(5):224-35.

17. Martyn H, Barrett A, Trotman P, Nicholson H. Medical students' responses to the dissection of the heart and brain: a dialogue on the seat of the soul. Clin Anat. 2012; 25(3):407-13. 
18. Arraez-Aybar LA, Casado-Morales MI, Castano-Collado G. Anxiety and dissection of the human cadaver: an unsolvable relationship? Anat Rec B New Anat. 2004; 279(1):16-23.

19. Pandey P, Zimitat C. Medical students' learning of anatomy: memorisation, understanding and visualisation. Med Educ. 2007; 41(1):7-14.

20. Marker DR, Juluru K, Long C, Magid D. Strategic improvements for gross anatomy web-based teaching. Anat Res Int. 2012:146262. doi: 10.1155/2012/146262

21. Rizzolo L, Stewart WB. Should we continue teaching anatomy by dissection when...? Anat Rec B New Anat. 2006; 289(6):215-8.

22. Guvençer MU, Sayhan S, Derel NA, Tet S, Yucesoy K, Arda MN. Simulation of cerebrovascular circulation in the human cadaver for surgical neuroanatomy training. Turk. Neurosurg. 2007; 17(7):243-6.

23. Notaris M, Topczewski T, Angelis MD, Ensenat J, Alobid I, Gondolbleu AM, et al. Anatomic skull base education using advanced neuroimaging techniques. World Neurosurg. 2013; 79(2):e16-23.

24. Yamato $H$, Nakashima T, Kikuta A, Kunugita N, Arashidani $K$, Nagafuchi $Y$, et al. A novel local ventilation system to reduce the levels of formaldehyde exposure during a gross anatomy dissection course and its evaluation using real-time monitoring. J Occup Health. 2005; 47(5):450-3.

25. Ohmichi K, Matsuno $Y$, Miyaso $H$, Yammamoto $H$, Toriuchi $M$, Shimane $M$, et al. Pillot study of a dissection table for gross anatomy laboratory equipped with a photocatalytic device that decomposes formaldehyde. J Occup Health. 2007; 49(6):499-503.

26. Hisamitsu M, Okamoto Y, Chaozono H, Onekura S, Sakurai D, Horiguchi S, et al. The influence of environmental exposure to formaldehyde in nasal mucosa of medical students during cadaver dissection. Allergol Int. 2011; 60(3):373-9.

27. Trelease R. Anatomy meets architecture: designing new laboratories for new anatomists. Anat Rec B New Anat. 2006; 289(6):241-54.

28. Demiryurek D, Bayramaglu A, Ustaçelebi S. Infective agents in fixed human cadavers: a brief review and suggested guidelines. Anat Rec. 2002; 269(4):194-7.

29. Topp KS. Prosection vs. dissection, the debate continues: rebuttal to granger. Anat Rec B New Anat. 2004; 281(1):12-4.

30. Melo E, Pinheiro J. Procedimentos legais e protocolos para utilização de cadáveres no ensino de anatomia em Pernambuco. Rev Bras Educ Med. 2010; 34(2):315-23.

31. Jones DG, Whitaker MI. Anatomy's use of unclaimed bodies: reasons against continued dependence on an ethically dubious practice. Clin Anat. 2012; 25(2):246-54.

32. Anyanwu GE, Udemezue OO, Obikili EN. Dark age of sourcing cadavers in developing countries: a nigerian survey. Clin Anat. 2011; 24(7):831-6.

33. Hildebrandt S. Anatomy in the third reich: careers disrupted by national socialist policies. Ann Anat. 2012; 194(3):251-6.

34. Fitzgerald MJT. Undergraduate medical anatomy teaching. J Anat. 1992; 180(Pt1):203-9.

35. Winkelmann A. Anatomical dissection as a teaching method in medical school: a review of the evidence. Med Educ. 2007; 41(1):15-22. 
Marques Pontinha C, Soeiro C. La disecación como herramienta pedagógica en la enseñanza de la Anatomía en Portugal. Interface (Botucatu). 2014; 18(48):165-75.

A lo largo de la historia, la importancia de la utilización de cadáveres humanos para la enseñanza y la investigación no ha sido un consenso. En el pasado, la obtención de los cadáveres indispensables para la enseñanza contaba con el recurso de cadáveres de presos, de no reclamados y del robo/compra de ellos. Más allá de la inadmisibilidad ética y jurídica de estas soluciones, ellas se mostraron insuficientes para las necesidades de las escuelas médicas. En las últimas décadas, la conciencia global de la legitimidad de la donación de cadáveres se fue intensificando, considerándose hoy día una forma digna de suplir esa falta. En este artículo se realizó una revisión de la literatura con el objetivo de hacer una reseña histórica, jurídica y pedagógica sobre la importancia de la utilización de cadáveres humanos en la enseñanza de Anatomía Humana en los cursos de Medicina, incluyendo en Portugal principalmente el recursos para la disecación cadavérica en complemento con otras herramientas pedagógicas.

Palabras-clave: Anatomía. Cadáver. Disecación. Donación. Educación Médica.

Recebido em 20/06/13. Aprovado em 30/10/13. 
